\title{
MANDIBULO-OCULO-FACIAL DYSCEPHALY*
}

\author{
BY \\ S. P. SRIVASTAVA, S. C. JAIN, AND H. V. NEMA $\dagger$ \\ Department of Ophthalmology, Gajra Raja Medical College, Gwalior, India
}

CONGENITAL anomalies of the skull and face are usually associated with congenital anomalies of the eye. Several cases are recorded in the literature of a specific variety, characterized by dyscephaly with bird-like face, dental anomalies, dwarfism, hypotrichosis, atrophy of skin, microphthalmos, microcornea, and congenital cataract. The first such case was reported by Aubry (1893) under the name of sutural congenital alopecia. Hallermann (1948), who reported two such cases, and Streiff (1950) distinguished this syndrome from mandibulo-facial dysostosis of Franceschetti. It was first fully annotated by Ullrich and Fremerey-Dohna (1953), who described the syndrome as a dyscephaly with congenital cataract and hypotrichosis. They collected nine cases of this syndrome from the literature, including one of their own. Blodi (1957) reported two cases under the name of mandibulo-facial dysostosis. François (1958) increased the number of reported cases to 21, including nine previously reported by Ullrich and Fremerey-Dohna and two by Blodi, and he added another case seen by himself and described as a new syndrome. Falls and Schull (1960) described another six cases under the heading of Hallermann-Streiff's syndrome, bringing the total number reported to 28 (see Table, overleaf). Out of these 28 cases, Cases 4 and 18 and 5 and 28 are the same two patients reported by different authors at different ages. Hence the actual number of cases reported in the literature is only 26 . The present case is a further addition to this series and is the first to be reported from India.

Duke-Elder (1964a) has described this syndrome under the heading of mandibulooculo-facial dyscephaly, and has classified such cases into two types-one exhibits marked hypoplasia of the mandible, a prominent parrot-beak nose giving a bird-like face, congenital cataract, microcornea, and microphthalmos, which he has labelled mandibulo-oculo-facial dysmorphia. The other type has, in addition to the above characteristics, more generalized anomalies including dwarfism (nanism), dental deformities, nasal anomalies, atrophy of the skin of the face, with hypotrichosis particularly of the brows and scalp, which Duke-Elder has designated mandibulooculo-facial dyscephaly.

François (1958) listed the following seven essential signs constituting this syndrome: (1) Dyscephaly and bird-face. (2) Dental anomalies. (3) Proportionate nanism. (4) Hypotrichosis. (5) Atrophy of skin. (6) Bilateral microphthalmos. (7) Cataract. In addition, he mentioned the following five negative signs which differentiate the syndrome from other related mandibulo-facial dysostoses and

* Received for publication May 10, 1965

† Present address: Muslim University Institute of Ophthalmology, Aligarh, India. 


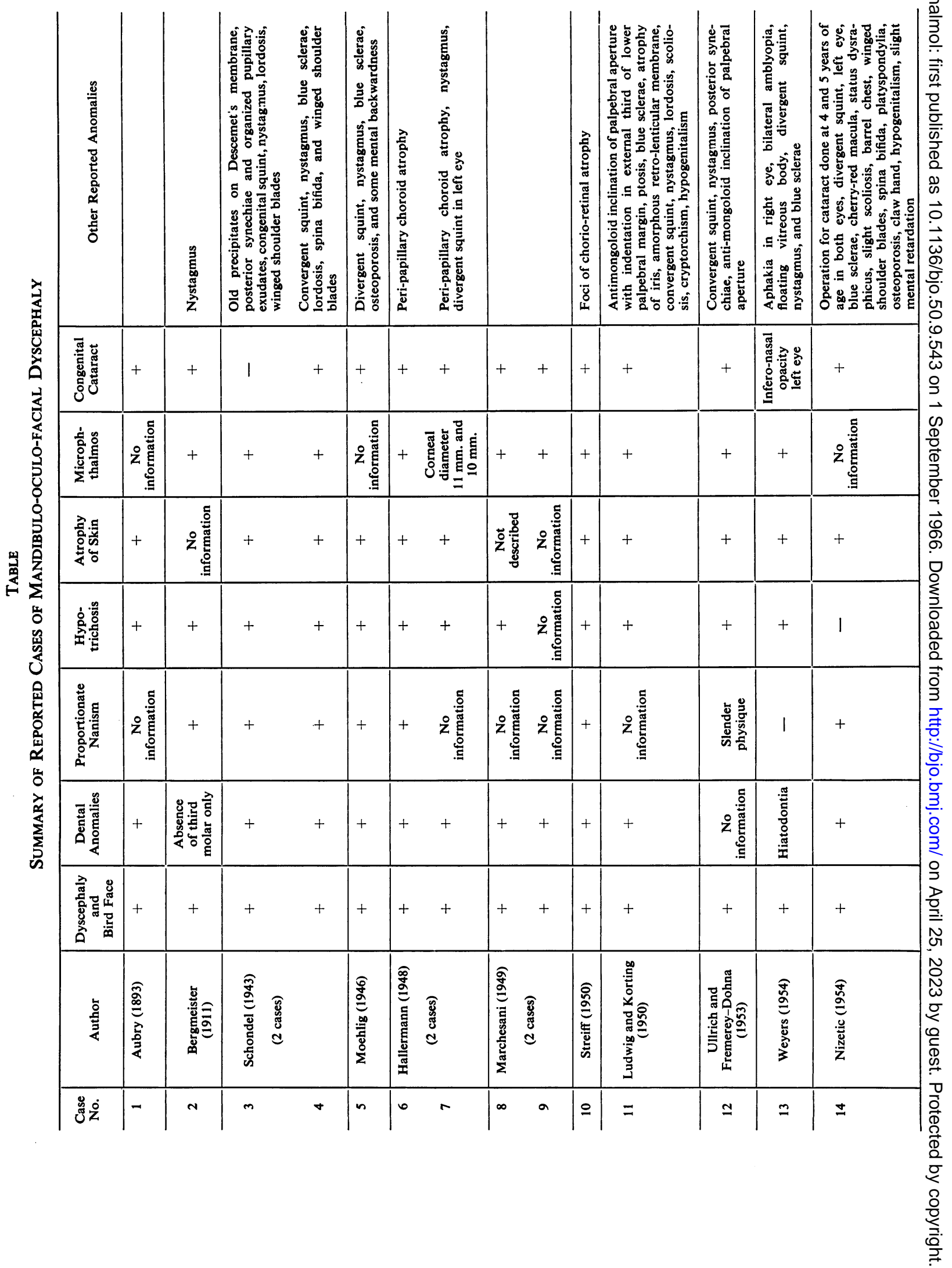




\begin{tabular}{|c|c|c|c|c|c|c|c|c|c|c|c|c|c|}
\hline 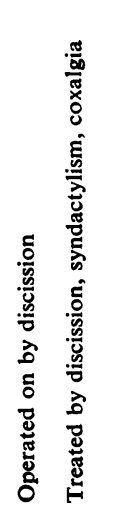 & 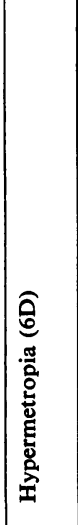 & 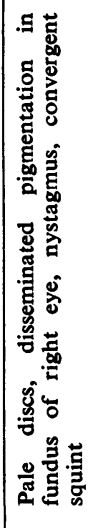 & 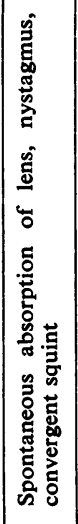 & 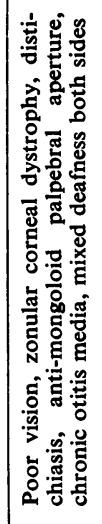 & 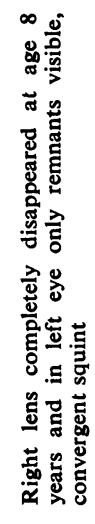 & 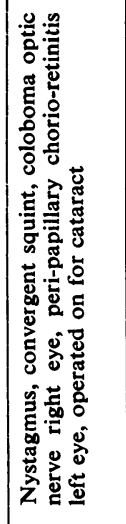 & 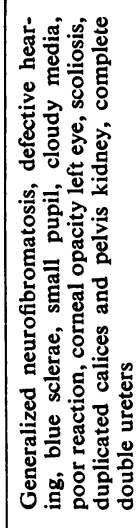 & 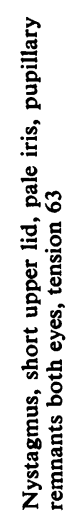 & 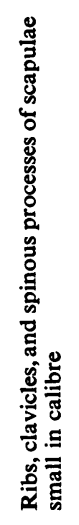 & 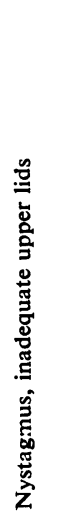 & 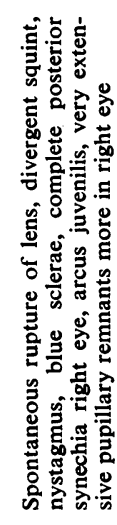 & 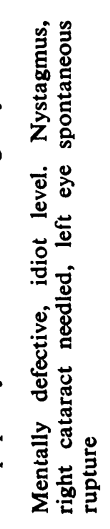 & 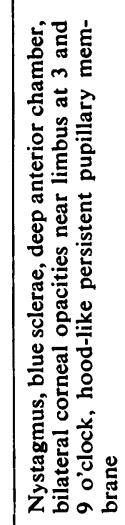 \\
\hline++ & + & + & + & + & + & + & 1 & + & + & + & + & + & 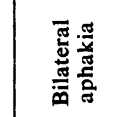 \\
\hline ż & + & + & + & + & + & 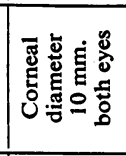 & 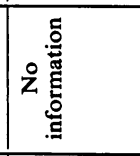 & + & + & 1 & + & + & + \\
\hline++ & 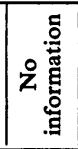 & + & + & 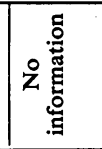 & 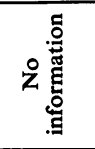 & + & + & + & 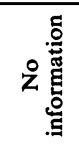 & + & + & + & + \\
\hline++ & + & + & + & + & + & + & + & ż & 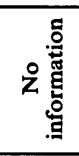 & 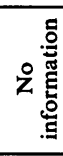 & + & + & + \\
\hline $1+$ & + & + & + & + & + & + & + & 䓀 & + & + & + & + & + \\
\hline 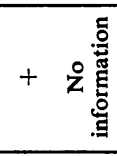 & 总 & 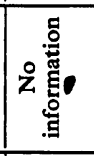 & 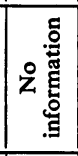 & 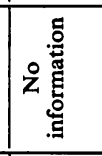 & + & + & 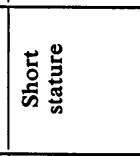 & + & + & 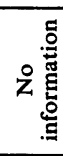 & + & + & + \\
\hline++ & + & + & + & + & + & + & + & + & + & + & + & + & + \\
\hline 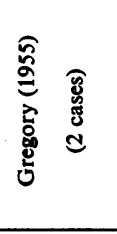 & 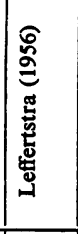 & 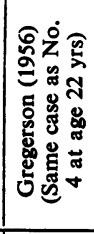 & 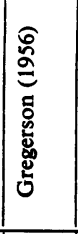 & 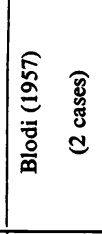 & & 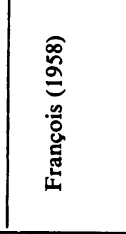 & 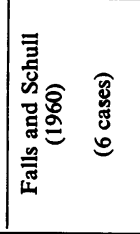 & & & & & 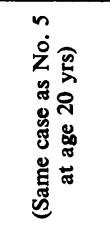 & 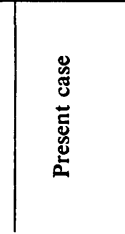 \\
\hline$\simeq$ & $=$ & $\infty$ & 2 & \% & $\bar{\pi}$ & $\pi$ & $\approx$ & $\ddot{A}$ & $\approx$ & i & $\hat{\lambda}$ & $\stackrel{\sim}{\sim}$ & สి \\
\hline
\end{tabular}


ectodermal aplasia and dysplasia: (1) Absence of anomalies of the ears. (2) Absence of the anomalies of the palpebral aperture. (3) Absence of muscular atrophy, chronic arthritis, and deformities of joints or premature arteriosclerosis, as seen in progeria. (4) Absence of anomalies of the nails and extremities, as seen in certain ectodermal dysplasia and dyscephaly. (5) Absence of mental backwardness and any neurological defect.

The present case shows all these characteristic features except that in place of congenital cataract there is a total absence of the lens in both eyes.

\section{Case Report}

An unmarried Hindu female aged 35 years came to the ophthalmic out-patients' department, Jai Arogya Hospital, Gwalior, with her father with a history of defective vision in both eyes since birth. She had been born at full term and there was no history of any intercurrent illness during her mother's pregnancy. At birth there was scarcely any hair and there were no eyebrows or eyelashes; her eyes were small. One tooth was present at the time of birth and all the primary teeth erupted, but were replaced by only a few permanent teeth. The patient's father, aged 78 , displayed no abnormality (Fig. 1). Her mother had died at the age of 36, but was reported to have been normal. Her one brother, aged 40, and two sisters, of whom one had died at the age of 19 years and the other at 33 years, were normal. There was no family history of any consanguinity or any other congenital anomaly.

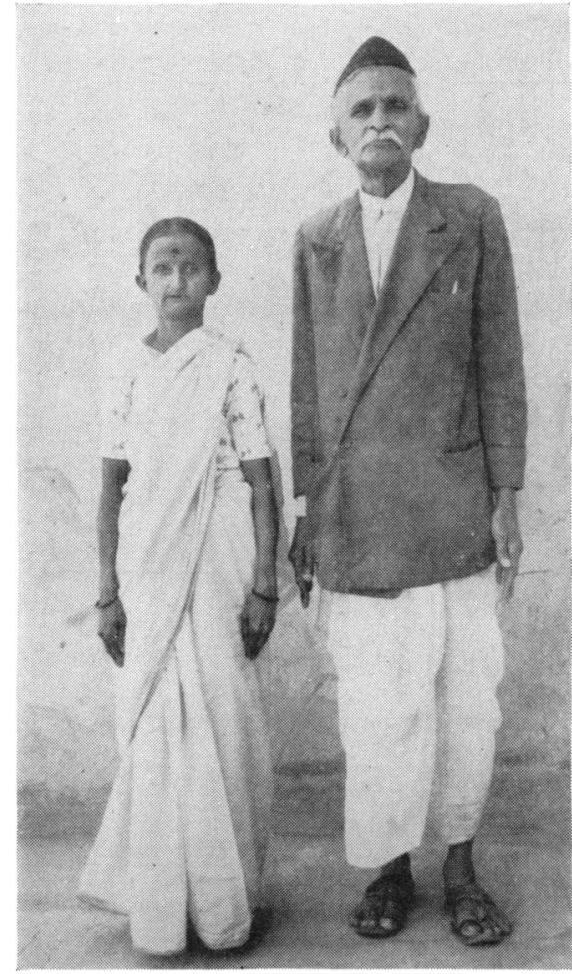

Physical examination revealed that the patient was of short stature, $4 \mathrm{ft} 3 \mathrm{in}$. in height and only $54 \mathrm{lb}$. in weight. She was co-operative and very intelligent. Her head was small and brachycephalic with scanty hair, particularly at the temples. Her face was small. There was marked hypoplasia of the mandible, a prominent thin and pointed parrot-beak nose, giving a bird-like appearance to the face. There were no eyebrows and no eyelashes. The skin was delicate with marked wrinkling over the forehead. It was atrophic, thin, and discoloured over the nose. The general appearance was that of a wizened old owoman (Fig. 2, opposite). There were only four teeth in the upper jaw (two premolars on each side) and three in the lower jaw (one premolar and two canines). The rest of the teeth had not erupted.

FIG. 1.-The patient with her father.

Examination of the cardiovascular system, central nervous system, respiratory system, and gastro-intestinal tract revealed nothing abnormal. Gynaecological examination showed the cervix and uterus to be of small size. Menstrual history was normal but the menses were scanty. The breasts were underdeveloped. 


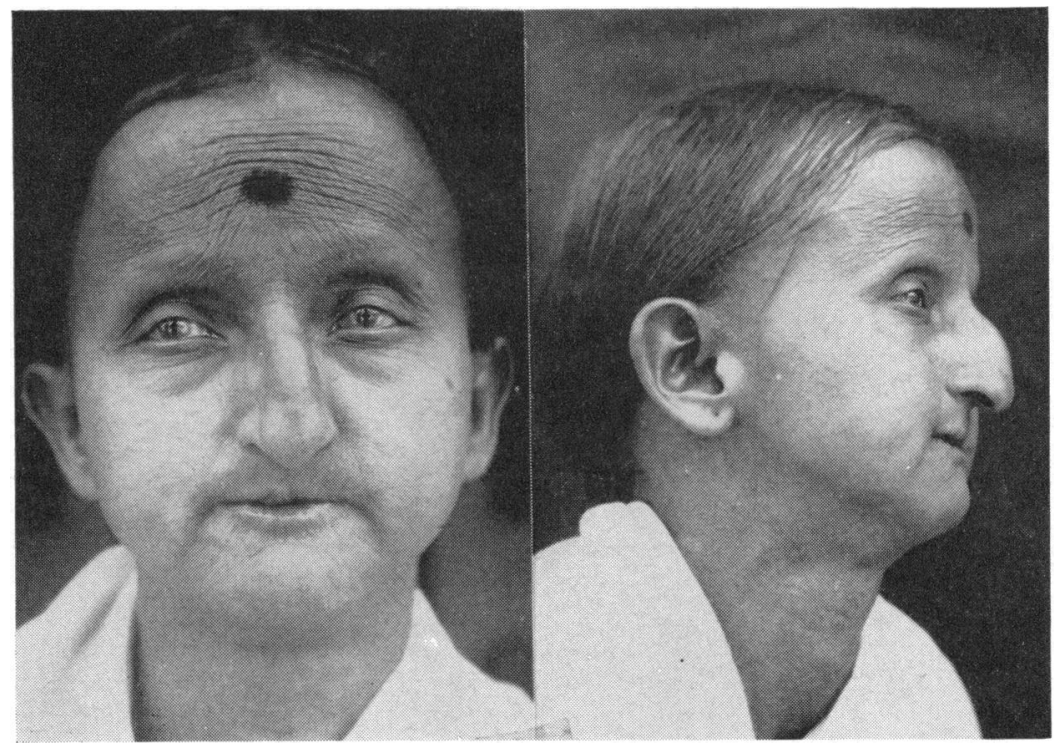

FIG. 2.-Facial appearance of the patient.

Examination of the Eyes.-There was microphthalmos with microcornea and horizontal nystagmus in both eyes. The sclera showed a bluish discoloration. There were small patches of corneal opacity on the cornea near the limbus at the 3 and 9 o'clock positions in both eyes, showing calcareous degeneration. The anterior chamber was very deep in both eyes. The iris was slightly atrophic. The most interesting finding was a peculiar type of persistent pupillary membrane shaped like a small semilunar hood, arising from the collarette and extending from 11 o'clock to 3 o'clock in the right eye and from 9 o'clock to 1 o'clock in the left eye, covering the inner and upper quadrants of the pupillary margin in both eyes (Fig. 3). The pupils were small, jet black, did not react to light, and could not be dilated, even on atropinization. Slit-lamp examination revealed a total absence of the lens in both eyes. There was no evidence of any capsular remnants. The anterior hyaloid face was normal and intact. The fundus could not be seen properly because of the small size of the pupil and rapid nystagmus. The visual acuity was $2 / 60$ in both eyes, improving to $6 / 36$ with $+8 \mathrm{D}$ sph.
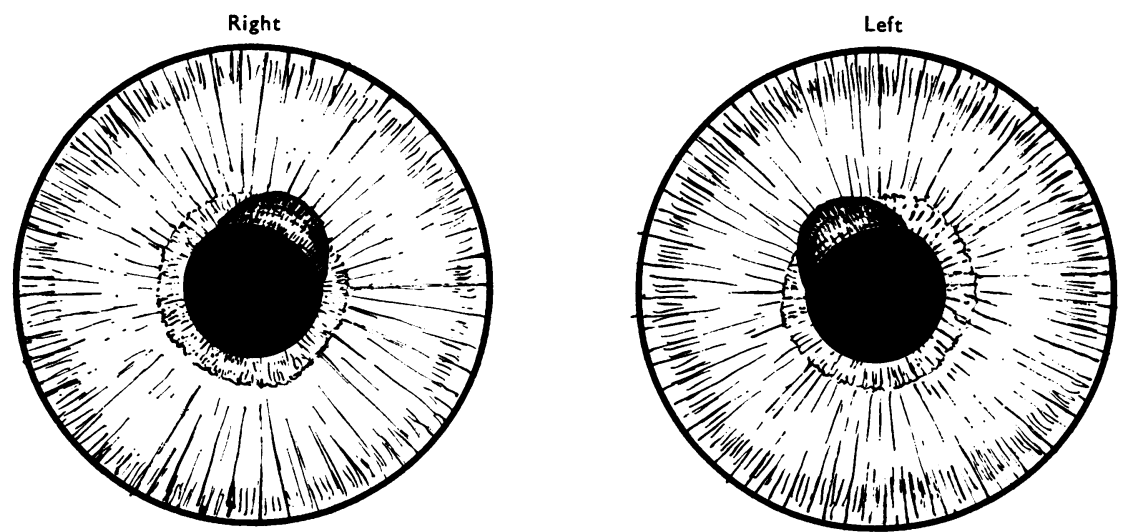

FIG. 3.-Drawings to show persistent pupillary membrane.

Investigations.-Examination of blood and urine normal. Kahn test negative. 
Radiography revealed a small skull with marked hypoplasia of the mandible. The maxillary bones on both sides were also underdeveloped and showed small maxillary sinuses (Fig. 4).

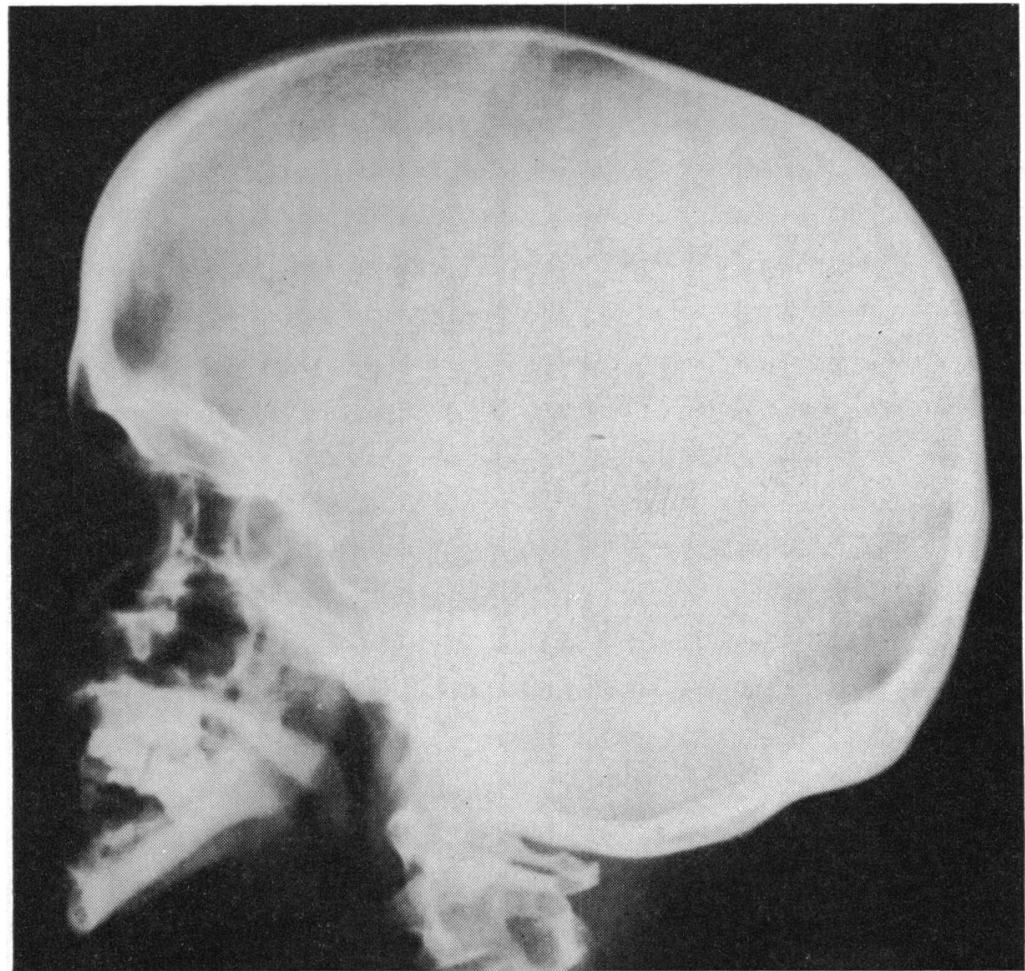

(a)

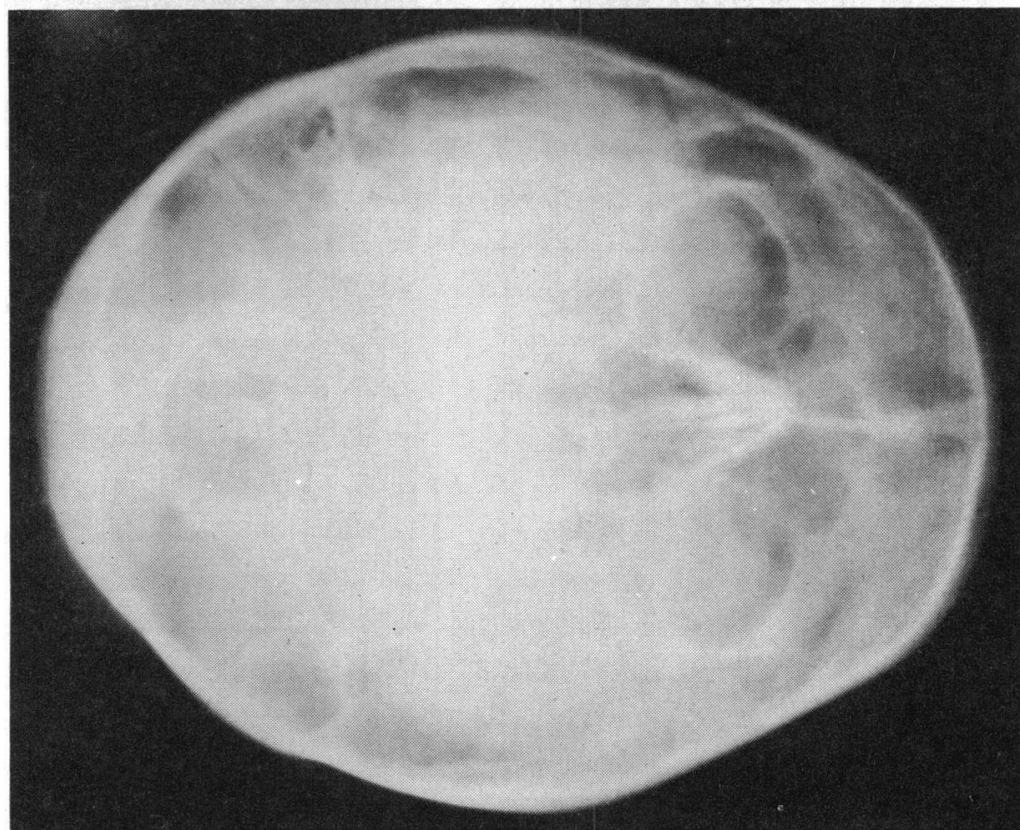

(b)

Fig. 4.-Radiographs showing small skull, hypoplasia of mandible, and small maxillary bones and sinuses. (a) lateral view; (b) submento-occipital view. 


\section{Discussion}

The aetiology of this syndrome is obscure. That it could be genetic and hereditary is not substantiated by the fact that all the cases reported so far were sporadic, as was also the present case. The fact that most of these patients remained unmarried because of their unattractive physical appearance and that none of them had any offspring does not totally exclude this factor. François (1958) and Ullrich and Fremerey-Dohna (1953) have suggested that it may be either a recessive affection or a mutation. Falls and Schull (1960) consider recessive affection as unlikely in view of the sporadic occurrence and the total absence of consanguineous marriages amongst the patients reported. They argue that to fit the present data into the recessive mould of an inheritance pattern requires invoking the subsidiary hypothesis of reduced penetrance, which is not only unsatisfying but in their estimation almost certainly unjustified. They think that the second genetic interpretation, i.e. mutation, would appear to be more probable, although not demonstrable because of the absence of offspring in these cases. They have suggested an alternative genetic explanation of chromosomal aberration in view of the recent demonstration that mongolian idiots have a supernumerary chromosome and because this syndrome has some similar characteristics.

Also, the influence of endogenous and exogenous factors operating during pregnancy is discounted by the absence of any such factor operating in the reported cases and in our present case. In one case only (Falls and Schull, 1960) was there a clear history of exposure to measles in the first trimester, but the mother did not suffer from any disease during pregnancy and she had had rubella previously. Therefore in this case, too, there is no conclusive evidence to show that any exogenous aetiological agent is in any way related to this syndrome. Duke-Elder (1964b) states that whatever may be the cause it must in most cases be operative before the end of the organo-genetic period to produce so many widespread congenital anomalies.

From the Table it will be clear that there is no hard and fast line dividing these cases into two types, as stated by Duke-Elder (1964a). Most of the cases show a combination of localized and generalized congenital anomalies although individual defects may be absent in a particular case. There is no case which shows purely localized anomalies without any generalized deformities. The details of the cases of Hallermann (1948) and Streiff (1950) as reported by François (1958) and which Duke-Elder (1964a) has included under mandibulo-facial-ocular dysmorphia show a number of generalized deformities like nanism, dental anomalies, hypotrichosis, and atrophy of the skin. Only nanism was not shown to be present in one of the two cases reported by Hallermann.

The present case shows a complete absence of the lens in both eyes. Falls and Schull (1960) have reported the spontaneous rupture and absorption of the cataractous lens in two of their cases, but in the present case there was no evidence of any capsular remnants or shreds on slit-lamp examination and the pupillary area was perfectly clear. There was no history of any eye operation, the patient's vision being the same from the very beginning. It can be concluded therefore that the lens was absent in this case from birth. The other interesting ocular finding was a peculiar type of persistent pupillary membrane in the shape of a semilunar hood. Only in two other cases (Case nos 24 and 27 in the Table) was a persistent pupillary membrane present.

\section{Summary}

A case of mandibulo-oculo-facial dyscephaly is presented. The literature is reviewed and the aetiology discussed. There was bilateral absence of the lens and a peculiar type of persistent pupillary membrane in the form of a semilunar hood, a finding not hitherto reported.

\section{REFERENCES}

Aubry, M. (1893). Ann. derm. syph., 3 sér., 4, 899.

Blodi, F. C. (1957). A.M.A. Arch. Ophthal., 57, 593.

Duke-Elder, S. (1964a). "System of Ophthalmology", vol. 3, pt 2, p. 1022. Kimpton, London. (1964b). Ibid., p. 1011.

Falls, H. F., and Schull, W. J. (1960). A.M.A. Arch. Ophthal., 63, 409.

FrançOIS, J. (1958). Ibid., 60, 842.

Hallermann, W. (1948). Klin. Mbl. Augenheilk., 113, 315.

STreifF, E. B. (1950). Ophthalmologica (Basel), $120,79$.

Ullrich, O., and Fremerey-Dohna, H. (1953). I Ibid., 125, 73. 